\title{
Investigation of electropolishing characteristics of tungsten in eco- friendly sodium hydroxide aqueous solution
}

\author{
Wei Han ${ }^{1} \cdot$ Feng-Zhou Fang ${ }^{1,2}$ (i)
}

Received: 2 February 2020/Revised: 17 March 2020 / Accepted: 4 May 2020/Published online: 26 May 2020

(C) The Author(s) 2020

\begin{abstract}
In this study, an eco-friendly electrolyte for electropolishing tungsten and the minimum material removal depth on the electropolished tungsten surface are investigated using an electrochemical etching method. Using a concentrated acid electrolyte, the polarization curve and current density transient are observed. For a $\mathrm{NaOH}$ electrolyte, the effects of interelectrode gap and electrolyte concentration on electropolishing are investigated. The differences in electropolishing characteristics are compared among different electrolyte types. Microholes are etched on the electropolished tungsten surface to determine the minimum material removal depth on the tungsten surface. Experimental results indicate the color effect due to a change in the thickness of the oxide film on the tungsten surface after electropolishing with a concentrated acid electrolyte. The surface roughness decreases with the interelectrode gap width owing to the increased current density when using the $\mathrm{NaOH}$ electrolyte. However, the electropolishing effect is less prominent with a significantly smaller gap because the generated bubbles are unable to escape from the narrow working gap in time. A material removal depth of less than $10 \mathrm{~nm}$ is achieved on the tungsten surface in an area of diameter $300 \mu \mathrm{m}$, using the electrochemical etching method.
\end{abstract}

Feng-Zhou Fang

fengzhou.fang@ucd.ie

1 Centre of Micro/Nano manufacturing Technology (MNMTDublin), University College Dublin, Dublin 4, Ireland

2 State Key Laboratory of Precision Measuring Technology and Instruments, Centre of Micro/Nano Manufacturing Technology (MNMT), Tianjin University, Tianjin 300072, People's Republic of China
Keywords Electropolishing $\cdot \mathrm{NaOH}$ solution $\cdot$ Surface roughness $\cdot$ Tungsten $\cdot$ Etching

\section{Introduction}

Tungsten has the highest melting point of all available metals with a melting temperature at $3422{ }^{\circ} \mathrm{C}$ and is applied extensively in various fields, such as arc-welding electrodes [1,2] and heat-resistant coatings [3]. Furthermore, it is the most typically used material for preparing scanning probe microscopy and scanning tunneling spectroscopy probes owing to its good physical and chemical properties [4, 5]. Moreover, tungsten has high stiffness and good electrical conductivity and is generally used as tool electrodes in electrical discharge machining [6] and electrochemical machining (ECM) $[7,8]$.

As a hard-brittle material, tungsten is difficult to machine using conventional machining methods, such as cutting and grinding, owing to its low machinability $[9,10]$. It has been reported that the ultraprecision diamond cutting of tungsten is significantly affected by the adhesion of tungsten to the tool, rapid tool wear, and brittle fracture [11]. Hence, tungsten is typically machined using nonconventional machining methods. Wire electrical discharge machining (WEDM) is an effective solution for machining hard materials such as zirconium, titanium, and tungsten carbide, which are difficult to machine using conventional machining methods [12]; additionally, it is an alternative for tungsten machining [13, 14]. However, WEDM is a thermal process in which the material is removed by melting, and vaporization and the formation of a heat-affected layer on the machined surface are inevitable [15]. In addition, tool wear due to thermal processes occurs in 
WEDM, resulting in a deterioration in machining precision.

To polish tungsten, chemical-mechanical polishing (CMP) is often used, in which synergetic effects of chemical and mechanical interactions are involved to achieve global planarization [16, 17]. Bielmann et al. [18] reported that the tungsten removal rate increased with decreasing particle size and increasing solid loading. Larsen-Basse and Liang [19] studied the contributions of abrasion in the CMP of tungsten and concluded that it was a synergistic process of passive film removal by abrasives and the reformation of a film by the action-passive reaction of a bare surface with a slurry. Although a chemical reaction is involved in CMP, its fundamental is based on the traditional mechanical polishing process [20]. Slurry particles and polishing byproducts that are pressed onto the workpiece surface owing to mechanical forces are serious defects. It is still challenging to directly apply a polished workpiece by CMP because of the dirty surface; therefore, a post-CMP cleaning process is required. In addition, the low material removal rate and significant slurry consumption render CMP a high-cost polishing method [21].

Moreover, electropolishing, also known as electrochemical polishing, anodic polishing, or electrolytic polishing, is a promising method for polishing tungsten because the material is removed by electrochemical reactions, which is a non-mechanical contact and damage-free processes without considering the hardness and brittleness of a workpiece [22-24]. The electropolishing method has been applied extensively in the surface treatment of metals with complex features, such as coronary stents and niobium superconducting radio frequency cavities. As CMP, which is widely used for polishing tungsten, is a high-cost finishing method owing to its requirement of a large amount of consumed slurry, the electropolishing of tungsten in $\mathrm{NaOH}$ electrolyte is an effective alternative as electropolishing is an easy and simple approach. High polishing efficiency can be achieved by increasing the current density and no post-treatments are required compared with CMP. Schubert et al. [25] studied the anodic dissolution behavior of tungsten carbide in an alkaline electrolyte under electrochemical machining conditions and discovered that near the interface, an adherent, supersaturated, viscous film of polytungstates was formed, which was then continuously dissolved and reproduced. The anodic dissolution process of electropolishing tungsten has been studied by Wang et al. [21], and they discovered that electropolishing tungsten in a $\mathrm{NaOH}$ aqueous solution with different applied potentials could be categorized into three stages: etching, brightening, and pitting. However, it is noteworthy that electropolishing tungsten in a $\mathrm{NaOH}$ aqueous solution differs from the conventional electropolishing conducted in a concentrated acid electrolyte owing to the different physical and chemical characteristics of electrolytes used. In a concentrated acid electrolyte, a thick viscous film layer is formed on the workpiece surface because the dissolved metal ions cannot diffuse into the viscous bulk electrolyte in time [26]. Previous studies have not focused on the differences between electropolishing tungsten in a $\mathrm{NaOH}$ aqueous solution and the conventional electropolishing in a concentrated acid electrolyte [21, 27].

In this study, the electropolishing characteristics of tungsten were investigated using different types of electrolytes, i.e., the conventional concentrated acid electrolyte and a $\mathrm{NaOH}$ aqueous solution. Subsequently, the minimum value of the material removal depth on the tungsten surface was determined based on the electropolished tungsten surface using an electrochemical etching method. For the study using the concentrated acid electrolyte, the polarization curve and current density transient during electropolishing tungsten were characterized. For the study using the $\mathrm{NaOH}$ aqueous solution, the effects of the interelectrode gap width and electrolyte concentration on the electropolishing of tungsten were investigated. Holstein et al. [28] reported the achievable minimum dimension of $100 \mu \mathrm{m}$ of metallic tungsten adhesion elements in round and square-edged variations using the ECM method. In this study, microholes of diameter $300 \mu \mathrm{m}$ were etched on an electropolished tungsten surface to investigate the minimum material removal depth on the tungsten surface using the ECM method.

\section{Experimental approach}

\subsection{Material and solution}

Table 1 shows the electrolytes and electrodes used for electropolishing tungsten. The concentrated acid electrolyte was composed of a phosphoric acid aqueous

Table 1 Electrolytes and electrodes used for electropolishing tungsten

\begin{tabular}{|c|c|c|c|}
\hline Electrolyte type & Composition & Workpiece electrode & Tool electrode \\
\hline $\begin{array}{l}\text { Concentrated acid } \\
\text { electrolyte }\end{array}$ & $\mathrm{H}_{3} \mathrm{PO}_{4}(81 \%$ v:v) : Glycerol $=3: 1$ & $\begin{array}{l}\text { Tungsten wire } \\
\qquad(\varphi 1 \mathrm{~mm})\end{array}$ & $\begin{array}{l}\text { Copper sheet } \\
(30 \mathrm{~mm} \times 10 \mathrm{~mm} \times 0.1 \mathrm{~mm})\end{array}$ \\
\hline $\mathrm{NaOH}$ electrolyte & $\begin{array}{l}\mathrm{NaOH} \text { aqueous solution }(0.27 \mathrm{~mol} / \mathrm{L} \text {, } \\
0.5 \mathrm{~mol} / \mathrm{L})\end{array}$ & $\begin{array}{l}\text { Tungsten wire } \\
\qquad(\varphi 1 \mathrm{~mm})\end{array}$ & $\begin{array}{l}\text { Copper sheet } \\
(30 \mathrm{~mm} \times 10 \mathrm{~mm} \times 0.1 \mathrm{~mm})\end{array}$ \\
\hline
\end{tabular}


solution $\left(\mathrm{H}_{3} \mathrm{PO}_{4}, 81 \%\right.$ in volume ratio) and glycerol in the volume ratio of $3: 1$. The $\mathrm{NaOH}$ electrolyte was prepared by dissolving $\mathrm{NaOH}$ powder in distilled water to the concentrations of $0.27 \mathrm{~mol} / \mathrm{L}$ and $0.5 \mathrm{~mol} / \mathrm{L}$. The same workpiece and tool electrode were used for the two types of electrolytes. The workpiece electrode was tungsten wire with a diameter of $1 \mathrm{~mm}$ and was mounted in a resin of diameter $30 \mathrm{~mm}$ to expose only the end surface. Hence, the effective surface area was a circle of diameter $1 \mathrm{~mm}$ in the electropolishing. The tool electrode was a copper sheet measuring $30 \mathrm{~mm} \times 10 \mathrm{~mm} \times 0.1 \mathrm{~mm}$, and one side was insulated by tape to reduce the effects of stray currents.

Table 2 shows the electrolyte and electrodes used for the nanoscale etching of tungsten. The electropolished tungsten was used as a workpiece with the exposed end surface measuring $1 \mathrm{~mm}$ in diameter. Copper wire of diameter $300 \mu \mathrm{m}$ was used as the tool electrode and was mounted in a resin of diameter $30 \mathrm{~mm}$. The resin was visible owing to the easy observation of the electrodes' relative position. The mounted copper wire was ground and mechanically polished in sequence to obtain a smoother surface. The electropolishing of copper was performed in $\mathrm{H}_{3} \mathrm{PO}_{4}$ aqueous solution with a concentration of $81 \%$, and the tool electrode was the same as that shown in Table 1.

The surface morphology was characterized using a digital microscope (VHX-5000), and the surface topography was measured by a noncontact optical profile (NPFLEX). Contact mode atomic force microscopy (MFP3D) was used for the analysis of the image topography.

\subsection{Experimental method}

Figure 1 shows the experimental setup used for electropolishing in this study. A typical electrochemical cell with three electrodes was used, and the reference electrode was a $\mathrm{Ag} / \mathrm{AgCl}$ reference element surrounded by an electrolyte of $4 \mathrm{~mol} / \mathrm{L} \mathrm{KCl}$ aqueous solution saturated with $\mathrm{AgCl}$. A potentiostat/galvanostat (CS310) was used to supply the applied potential between the electrodes. A magnetic stir bar was used to stir the electrolyte at a stirring speed of $667 \mathrm{r} / \mathrm{min}$. The setup show in Fig. 1 was also used for the nanoscale etching of tungsten surface with a copper tool electrode mounted in resin.

Table 2 Electrolyte and electrodes used for the nanoscale etching of tungsten

\begin{tabular}{lcc}
\hline Electrolyte & Workpiece electrode & Tool electrode \\
\hline NaOH aqueous & Electropolished tungsten & Copper wire $(\varphi$ \\
solution $(0.5 \mathrm{~mol} / \mathrm{L})$ & wire $(\varphi 1 \mathrm{~mm})$ & $300 \mu \mathrm{m})$ \\
\hline
\end{tabular}

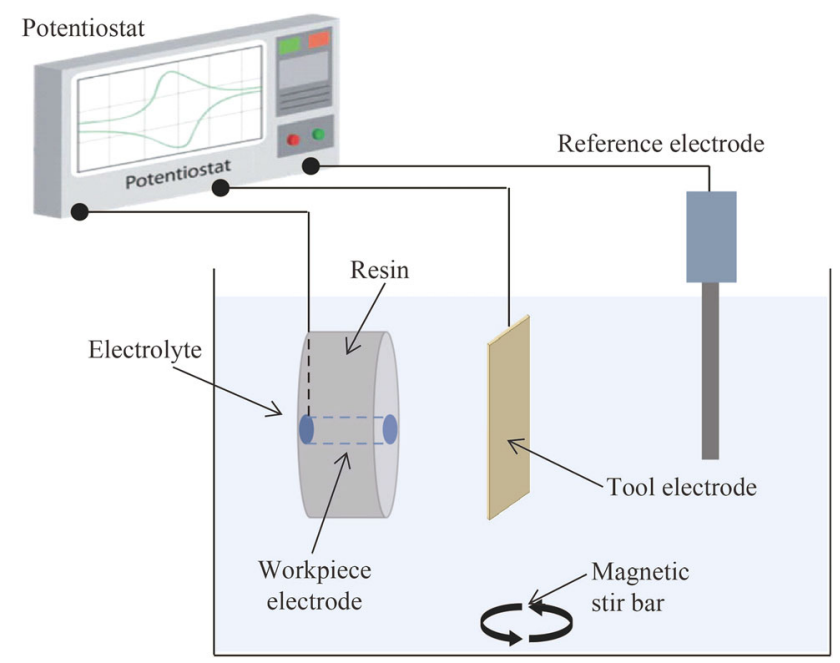

Fig. 1 Experimental setup used for electropolishing

It is crucial to reduce the initial surface roughness of a workpiece before electropolishing because the electropolishing method is limited in terms of polishing ability to improve the surface roughness [24]. The final electropolished surface is better with a lower initial surface roughness [29]. Therefore, the workpiece electrodes used in electropolishing were ground and mechanically polished prior to electropolishing to obtain a better electropolishing effect. They were uniformly ground with 600, 1200 , and 2 500 grit abrasive sandpaper sequentially and then mechanically polished using a colloidal silica polishing suspension of micro sizes $3 \mu \mathrm{m}$ and $<1 \mu \mathrm{m}$. Figure 2 shows the ground and mechanically polished tungsten surfaces. Because tungsten is a significantly hard material, scratches that form due to grinding could not be removed completely by the subsequent mechanical polishing, as shown in Fig. 2b. It was observed that the number of scratches in the vicinity of the edge was less than that at the center because the refresh of colloidal silica polishing suspension was more efficient during mechanical polishing.

Table 3 shows the experimental conditions used to study the effects of the interelectrode gap width and electrolyte concentration on the electropolishing of tungsten in $\mathrm{NaOH}$

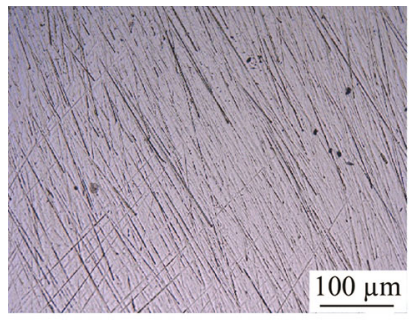

(a)

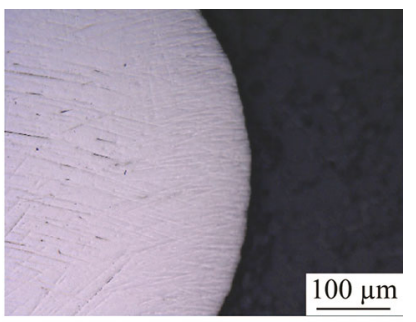

(b)
Fig. 2 a Ground and $\mathbf{b}$ mechanical polished tungsten surface 
Table 3 Experimental conditions used to study the influences of interelectrode gap width and electrolyte concentration on the electropolishing effect of tungsten in $\mathrm{NaOH}$ electrolyte

\begin{tabular}{ll}
\hline Parameter & Value \\
\hline Applied potential/V & 8 \\
$\begin{array}{l}\text { Electrolyte }(\mathrm{NaOH} \text { aq. }) \text { concentration/ } \\
\left(\mathrm{mol} \cdot \mathrm{L}^{-1}\right)\end{array}$ & $0.27,0.5$ \\
Electropolishing duration/s & $200,300,400,500$ \\
Interelectrode gap widths/mm & $0.15,0.5,1.0,1.5$ \\
\hline
\end{tabular}

electrolyte. The interelectrode gap width was varied to $0.15,0.5,1.0$, and $1.5 \mathrm{~mm}$, and the concentrations of the $\mathrm{NaOH}$ aqueous solution were $0.27 \mathrm{~mol} / \mathrm{L}$ and $0.5 \mathrm{~mol} / \mathrm{L}$. To determine the optimum applied potential, the potential was reduced step by step from the maximum value of $10 \mathrm{~V}$ supplied by the potentiostat/galvanostat while monitoring for a significant oscillation in the current density; a final potential of $8 \mathrm{~V}$ was decided.

Table 4 shows the experimental conditions used for the nanoscale etching of the tungsten surface. The electrolyte was a $\mathrm{NaOH}$ aqueous solution of concentration $0.5 \mathrm{~mol} / \mathrm{L}$. The interelectrode gap width was $0.3 \mathrm{~mm}$, and the stirring speed of the magnetic stir bar was $667 \mathrm{r} / \mathrm{min}$. The etching durations were $35 \mathrm{~s}$ and $75 \mathrm{~s}$. The surface quality of the tool electrode is critical in nanoscale etching because the surface shape of the tool electrode can be converted into the machined surface [30]. The copper tool electrode, which was used as a tool electrode for the nanoscale etching of the electropolished tungsten, was ground and mechanically polished sequentially based on the methods for preparing tungsten. Subsequently, electropolishing was performed to reduce the grain boundaries on the copper surface by optimizing the process parameters.

Figure 3 shows the copper tool surface after grinding and mechanical polishing. Grain boundaries can be observed clearly on the surface. Moreover, scratches appeared after the mechanical polishing. They were typically generated on the copper surface by the grinding process and most of them disappeared after the mechanical

Table 4 Experimental conditions used for the nanoscale etching of tungsten

\begin{tabular}{|c|c|}
\hline Parameter & Value \\
\hline Applied potential/V & 5 \\
\hline Electrolyte $(\mathrm{NaOH}$ aq. $)$ concentration/ $\left(\mathrm{mol} \cdot \mathrm{L}^{-1}\right)$ & 0.5 \\
\hline Inter-electrode gap width $/ \mathrm{mm}$ & 0.3 \\
\hline Stir speed $/\left(r \cdot \min ^{-1}\right)$ & 667 \\
\hline Etching duration/s & 35,75 \\
\hline
\end{tabular}

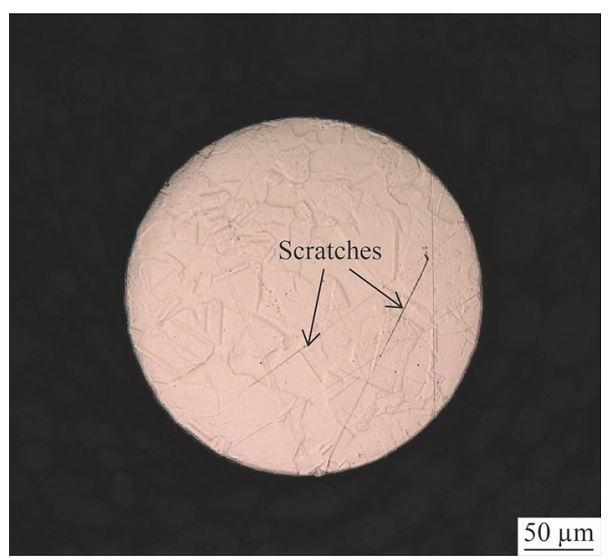

Fig. 3 Copper tool surface after mechanical polishing

polishing. The scratches shown in Fig. 3 might have generated during grinding, and the mechanical polishing failed to remove some significantly deep scratches caused by large abrasives during grinding. Furthermore, this might be caused by contaminative particles, such as abrasives from grinding, during the mechanical polishing. Because copper has a low hardness, scratches can be formed easily even when only a few contaminative particles exist in the polishing suspension. The mechanically polished surface shown in Fig. 3 was treated by electropolishing to obtain a significantly smooth surface.

\section{Results and discussion}

\subsection{Electropolishing tungsten in a concentrated acid electrolyte}

Figure 4 shows the polarization curve that was obtained by sweeping the applied potential from $3 \mathrm{~V}$ to $0 \mathrm{~V}$ (vs $\mathrm{Ag} /$ $\mathrm{AgCl}_{\text {sat }}$ ) at a scan rate of $-20 \mathrm{mV} / \mathrm{s}$, and the current density transient measured in the concentrated acid electrolyte. It has been reported that the potential must be swept from the positive values in the cathodic direction to obtain reproducible measurements [31]. Four typical potential regions, i.e., etching, passivation, limiting current density plateau, and gas evolution were observed on the polarization curve, as shown in Fig. 4a. The current density oscillated with a large amplitude in the gas evolution region because of the evolution of oxygen gas from the tungsten surface. Because the best electropolishing effect is typically obtained in the limiting current density plateau region [24], $2 \mathrm{~V}$ was applied as the potential for electropolishing. Figure $4 \mathrm{~b}$ shows the typical current density transient in electropolishing. The decrease in the current density at the initial stage was due to the generation of a thick oxide film layer on the workpiece surface. 


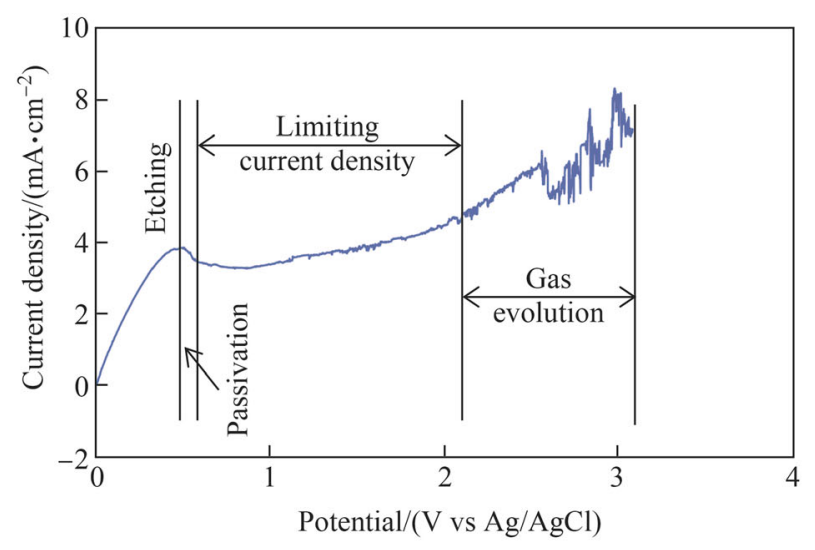

(a)

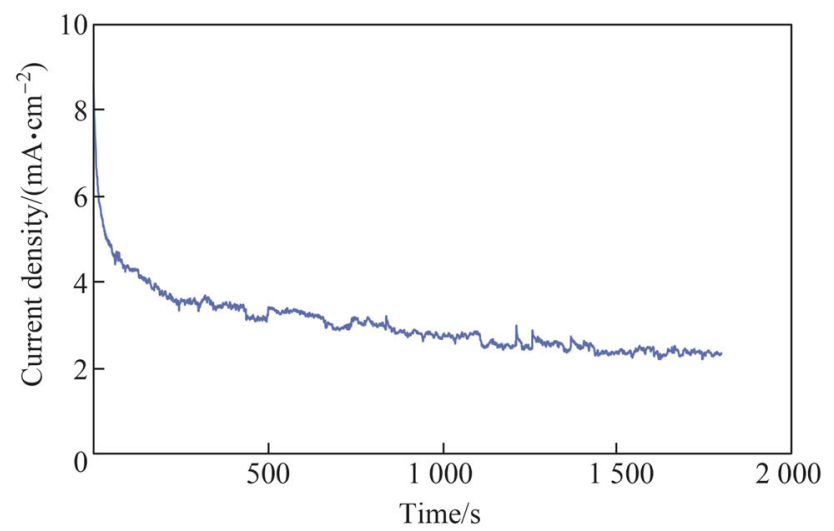

(b)

Fig. 4 a Polarization curve measured with the scan rate of $-20 \mathrm{mV} /$ $\mathrm{s}$ and potential range of 3-0 $\mathrm{V}$ and $\mathbf{b}$ current density transient with the applied potential of $2 \mathrm{~V}$ and electropolishing duration of $30 \mathrm{~min}$

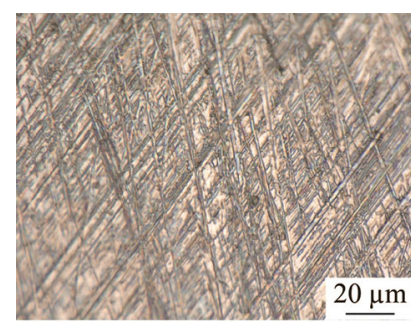

(a)

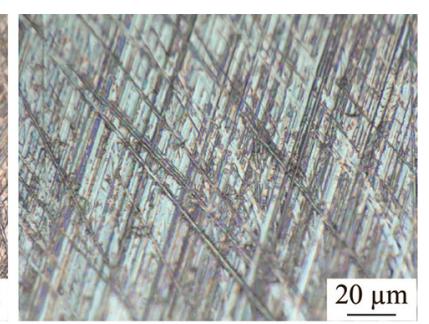

(b)
Fig. 5 Images of tungsten surface $\mathbf{a}$ before and $\mathbf{b}$ after electropolishing

Subsequently, it stabilized with increasing electropolishing duration because of the balance achieved between the generation and dissolution of the oxide film layer.

Figure 5 shows the images of the tungsten surface before and after electropolishing. The surface finish showed almost no improvement; therefore, it was concluded that a slight electropolishing effect occurred in tungsten electropolishing when the conventional concentrated acid electrolyte composed of $81 \%$ concentration
$\mathrm{H}_{3} \mathrm{PO}_{4}$ solution and glycerol in the volume ratio of $3: 1$. Because the thick oxide film caused a high interelectrode gap resistance, the current density was significantly low, as shown in Fig. 4, resulting in a low material removal rate and the electropolishing effect. The overall electrode reactions can be expressed by the following chemical reactions when electropolishing tungsten using the concentrated acid electrolyte [32, 33]

Cathode $2 \mathrm{H}^{+}+2 \mathrm{e}^{-} \rightarrow \mathrm{H}_{2}(\mathrm{~g})$

Anode $\mathrm{W}(\mathrm{s})+3 \mathrm{H}_{2} \mathrm{O}=\mathrm{WO}_{3}(\mathrm{~s})+6 \mathrm{H}^{+}+6 \mathrm{e}^{-}$

$\mathrm{WO}_{3}(\mathrm{~s})+\mathrm{H}_{2} \mathrm{O} \rightarrow \mathrm{WO}_{3} \cdot \mathrm{H}_{2} \mathrm{O}(\mathrm{s})=\mathrm{H}_{2} \mathrm{WO}_{4}(\mathrm{aq})$

The dissolution of the oxide film layer by reaction (3) is an extremely slow process, thereby resulting in the low material removal rate in electropolishing. It has been discovered that $\mathrm{WO}_{3}$ can be dissolved using $\mathrm{H}^{+}$when the solution $\mathrm{pH}$ is lower than 1 , based on the following reaction $[33,34]$

Cathode $\mathrm{WO}_{3}(\mathrm{~s})+\mathrm{H}^{+} \rightarrow \mathrm{WO}_{2} \mathrm{OH}^{+}(\mathrm{aq})$

However, the $\mathrm{pH}$ of the $81 \% \mathrm{H}_{3} \mathrm{PO}_{4}$ aqueous solution was between 1.0-1.6, resulting in the dissolution of the oxide film layer in $\mathrm{a}_{2} \mathrm{O}$-assisted process, as shown in reaction (3), with an extremely low dissolution rate; this is verified by the electropolished results shown in Fig. 5. Meanwhile, tungsten can be electropolished in a concentrated acid electrolyte of $\mathrm{pH}$ lower than 1 owing to the dissolution of the oxide film layer by reaction (4), which necessitates more investigation in the future.

Moreover, Fig. 5 shows that the surface color of tungsten changed after electropolishing though the electropolishing effect was not evident. Evans et al. [35] studied the composition and thickness of the colored oxide films on a stainless steel surface after they were immersed in a solution containing chromic and sulfuric acids at $70{ }^{\circ} \mathrm{C}$. It was reported that the colors on the steel surface area were produced by interference between the light reflected from the metal/film interface and that reflected from the film/air interface. The film thickness is changed as the reaction proceeds in the solution, thus producing changes in color. The electropolishing process failed to improve the tungsten surface significantly; however, the thickness of oxide film was changed, resulting in the different colors shown in Fig. 5b. The change of the oxide film layer could also be verified by the initial decrease in the current density transient shown in Fig. 4b.

\subsection{Electropolishing tungsten in $\mathrm{NaOH}$ aqueous solution}

Figure 6 shows the current density transitions with different interelectrode gap widths. At the large gap width of 


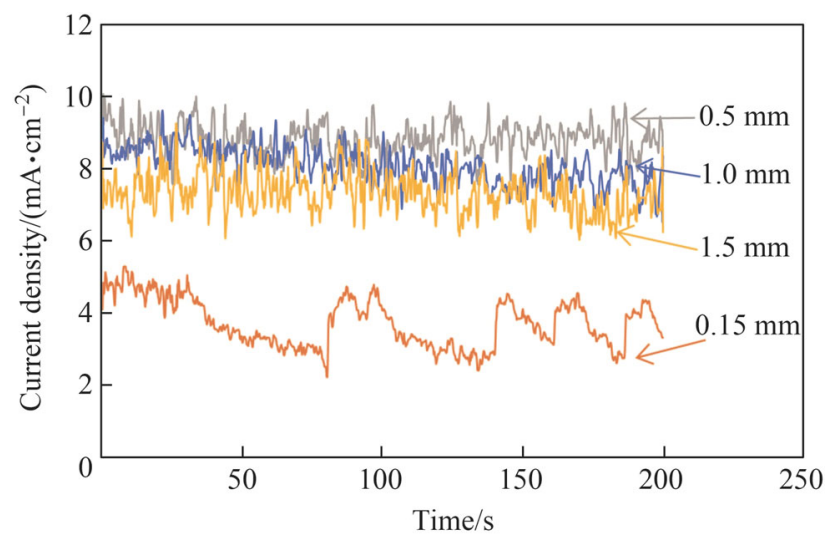

Fig. 6 Current density transitions with different interelectrode gap widths

$1.5 \mathrm{~mm}$, the current density decreased owing to the high gap resistance. It was discovered that the current density decreased significantly at the gap width of $0.15 \mathrm{~mm}$. This occurred because the gas produced by electrochemical reactions could not dissipate from the narrow working gap efficiently, resulting in a higher gap resistance and lower current density. Moreover, four spikes in the current density transition were observed at $82,140,161$, and $187 \mathrm{~s}$ at the gap width of $0.15 \mathrm{~mm}$. It was speculated that as the total number of generated gas bubbles increased with the electropolishing duration, some small gas bubbles merged to form a bigger bubble and then escaped from the narrow working gap under the action of electrolyte stirring, resulting in some fresh electrolytes flowing into the narrow working gap. Hence, the current density increased quickly owing to the decreased working gap resistance. Subsequently, the current density decreased slowly after the spike, as shown in Fig. 6, because new gas bubbles were generated and gathered in the narrow working gap again. Shimasaki and Kunieda [36] observed the gap phenomenon of ECM using transparent electrodes made of $\mathrm{SiC}$ single crystal as the cathode and discovered that the working gap was filled with gas bubbles within several milliseconds, which significantly affected the gap resistance and current density. Hence, for the electropolishing of tungsten, the interelectrode gap width should be optimized to avoid the effects of gas bubbles in a narrow working gap.

Moreover, it was discovered that the current density transitions in the $\mathrm{NaOH}$ aqueous solution differed from those in the concentrated acid electrolyte shown in Fig. 4b. Firstly, the current density was much higher when the $\mathrm{NaOH}$ aqueous solution was used. This might be due to the higher applied potential or the dissolution of the oxide film layer in the $\mathrm{NaOH}$ aqueous solution. When electropolishing tungsten with a $\mathrm{NaOH}$ aqueous solution, the overall electrode reactions can be expressed as follows [21, 37]
Cathode $6 \mathrm{H}_{2} \mathrm{O}+6 \mathrm{e}^{-} \rightarrow 3 \mathrm{H}_{2}(\mathrm{~g})+6 \mathrm{OH}^{-}$

Anode $\mathrm{W}(\mathrm{s})+6 \mathrm{OH}^{-} \rightarrow \mathrm{WO}_{3}(\mathrm{~s})+3 \mathrm{H}_{2} \mathrm{O}+6 \mathrm{e}^{-}$

$\mathrm{WO}_{3}(\mathrm{~s})+2 \mathrm{OH}^{-} \rightarrow \mathrm{WO}_{4}^{2-}+\mathrm{H}_{2} \mathrm{O}$

The oxide film layer can be dissolved rapidly on the tungsten surface by reaction (7) in the $\mathrm{NaOH}$ aqueous solution; subsequently, an obvious electropolishing effect can be obtained. An air-formed oxide film layer is generated on the tungsten surface before the electropolishing; therefore, reactions (3) and (7) should occur first when electropolishing tungsten in a concentrated acid electrolyte and $\mathrm{NaOH}$ aqueous solution, respectively. However, the oxide film layer can be easily dissolved by reaction (7) and the dissolution rate is extremely low owing to reaction (3). Therefore, the electropolishing of tungsten indicated a higher current density in the $\mathrm{NaOH}$ aqueous solution, as shown in Figs. 4 and 6.

Figure 7 shows the electropolished tungsten surfaces with different interelectrode gap widths. Figure 8 shows the topographies of the electropolished tungsten surfaces with the interelectrode gap widths of $0.15 \mathrm{~mm}$ and $1.0 \mathrm{~mm}$. With the interelectrode gap width of $0.15 \mathrm{~mm}$, some bulges were observed, as shown in Figs. 7a and 8a. The gas bubbles attached to these positions and protected the surface against dissolution during electropolishing process. Figure 9 shows the schematic diagram of the protection effect. In addition, Fig. $7 d$ shows that the electropolished surface was rougher at the interelectrode gap width was $1.5 \mathrm{~mm}$ because of the lower current density - a higher current density generates a better surface finish in ECM.

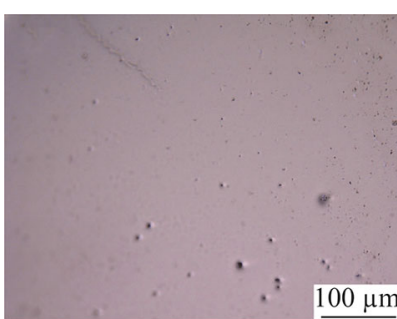

(a)

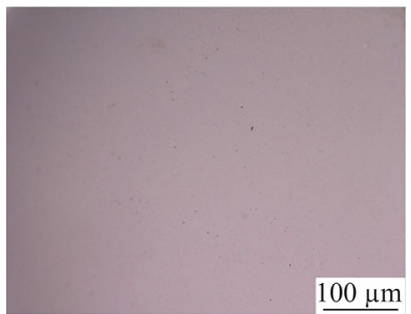

(c)

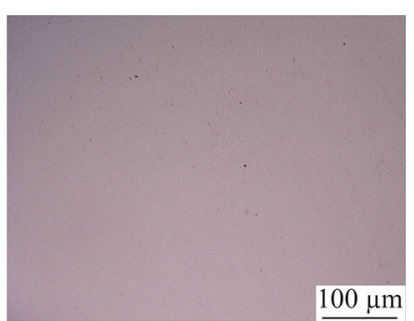

(b)

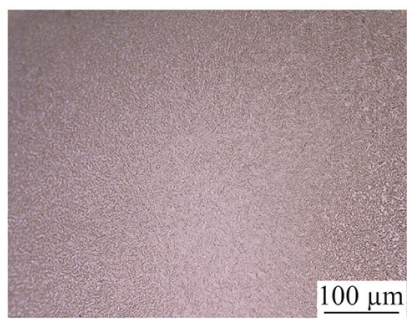

(d)
Fig. 7 Electropolished tungsten surfaces with different interelectrode gap widths of a $0.15 \mathrm{~mm}, \mathbf{b} 0.5 \mathrm{~mm}, \mathbf{c} 1.0 \mathrm{~mm}$ and $\mathbf{d} 1.5 \mathrm{~mm}$ 


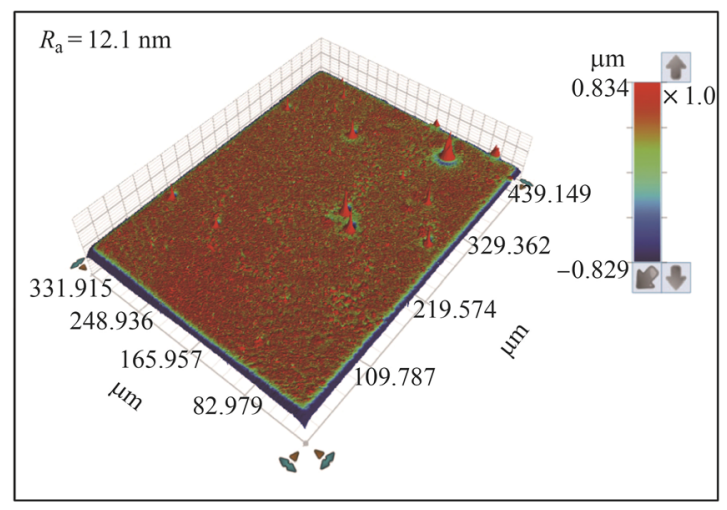

(a) Inter-electrode gap width of $0.15 \mathrm{~mm}$

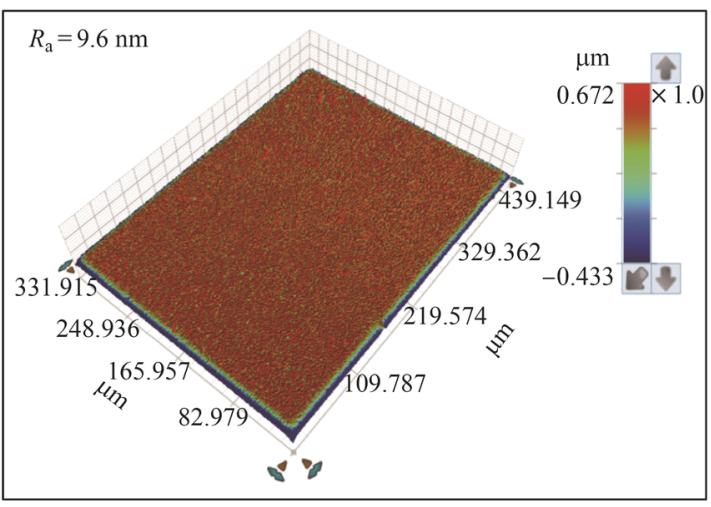

(b) Inter-electrode gap width of $1.0 \mathrm{~mm}$

Fig. 8 Topographies of electropolished tungsten surfaces with different interelectrode gap widths

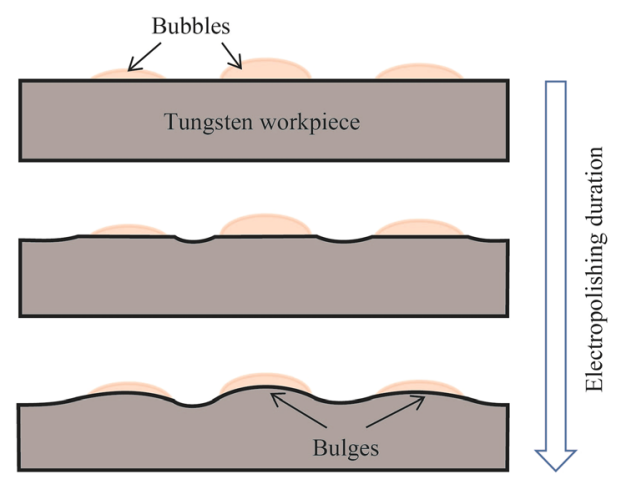

Fig. 9 Protection effect of gas bubbles on the tungsten surface in electropolishing

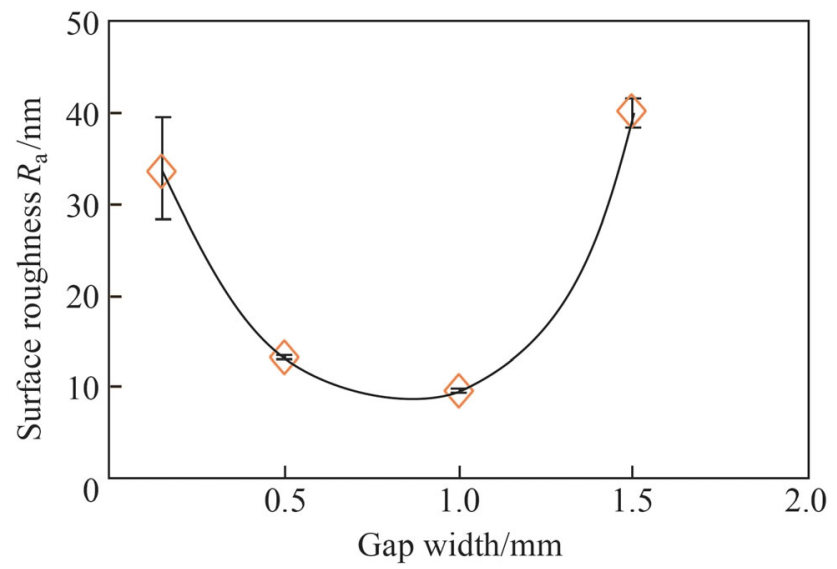

Fig. 10 Surface roughness $R_{\mathrm{a}}$ obtained with different interelectrode gap widths

With the optimized interelectrode gap width of $1.0 \mathrm{~mm}$, the surface roughness $R_{\mathrm{a}}$ decreased to $9.6 \mathrm{~nm}$, as shown in Fig. 8b. Figure 10 shows the $R_{\mathrm{a}}$ obtained using different interelectrode gap widths, and the optimized interelectrode gap of $1.0 \mathrm{~mm}$ generated the lowest surface roughness $R_{\mathrm{a}}$.

Figure 11 shows the electropolished tungsten surface with the $\mathrm{NaOH}$ concentration of $0.27 \mathrm{~mol} / \mathrm{L}$ and the electropolishing duration of $200 \mathrm{~s}$. The $R_{\mathrm{a}}$ was $26.2 \mathrm{~nm}$ (as shown in Fig. 6b), which was much rougher than the $R_{\mathrm{a}}$ of $9.6 \mathrm{~nm}$; it was obtained when the electrolyte concentration of $0.5 \mathrm{~mol} / \mathrm{L}$ was used for the same duration of $200 \mathrm{~s}$. The current density decreased with the electrolyte concentration owing to the reduced electrical conductivity, resulting in a lower material removal rate. Figure 12 shows the current density transitions with the $\mathrm{NaOH}$ concentrations of $0.27 \mathrm{~mol} / \mathrm{L}$ and $0.5 \mathrm{~mol} / \mathrm{L}$, which shows that the current density with the concentration of $0.27 \mathrm{~mol} / \mathrm{L}$ is half of that with the concentration of $0.5 \mathrm{~mol} / \mathrm{L}$. Therefore, the tungsten surface might not be surface treated sufficiently with the concentration of $0.27 \mathrm{~mol} / \mathrm{L}$ and duration of $200 \mathrm{~s}$. Figure 13 shows the electropolishing results with increased durations using the electrolyte concentration of $0.27 \mathrm{~mol} /$ L. As shown, the tungsten surfaces were similar for the durations of $400 \mathrm{~s}$ and $500 \mathrm{~s}$; this implied that the tungsten surface was sufficiently electropolished after $400 \mathrm{~s}$ with the electrolyte concentration of $0.27 \mathrm{~mol} / \mathrm{L}$. Figure 14 shows the three-dimensional (3D) plot of the electropolished tungsten surface based on a duration of $400 \mathrm{~s}$ and the $\mathrm{NaOH}$ concentration of $0.27 \mathrm{~mol} / \mathrm{L}$. A low $R_{\mathrm{a}}$ of $7.9 \mathrm{~nm}$ was obtained. Figure 15 shows the $R_{\mathrm{a}}$ obtained using different $\mathrm{NaOH}$ concentrations. The minimum $R_{\mathrm{a}}$ decreased from $9.6 \mathrm{~nm}$ to $7.5 \mathrm{~nm}$ when the $\mathrm{NaOH}$ concentration was decreased from $0.5 \mathrm{~mol} / \mathrm{L}$ to $0.27 \mathrm{~mol} / \mathrm{L}$. With the concentrated acid electrolyte, the effect of electrolyte concentration on the electropolishing effect is likely attributed to the concentration of the limitation species, which are responsible for the mass transportation limitation in the viscous film layer [24, 26]. However, a thick viscous film layer cannot be formed on the tungsten surface with the $\mathrm{NaOH}$ aqueous solution because the dissolved ions can diffuse away from the tungsten surface in time with a low viscosity of the $\mathrm{NaOH}$ electrolyte. Therefore, the effect of $\mathrm{NaOH}$ concentration on electropolishing cannot be explained by the mass transport limitation theory. 

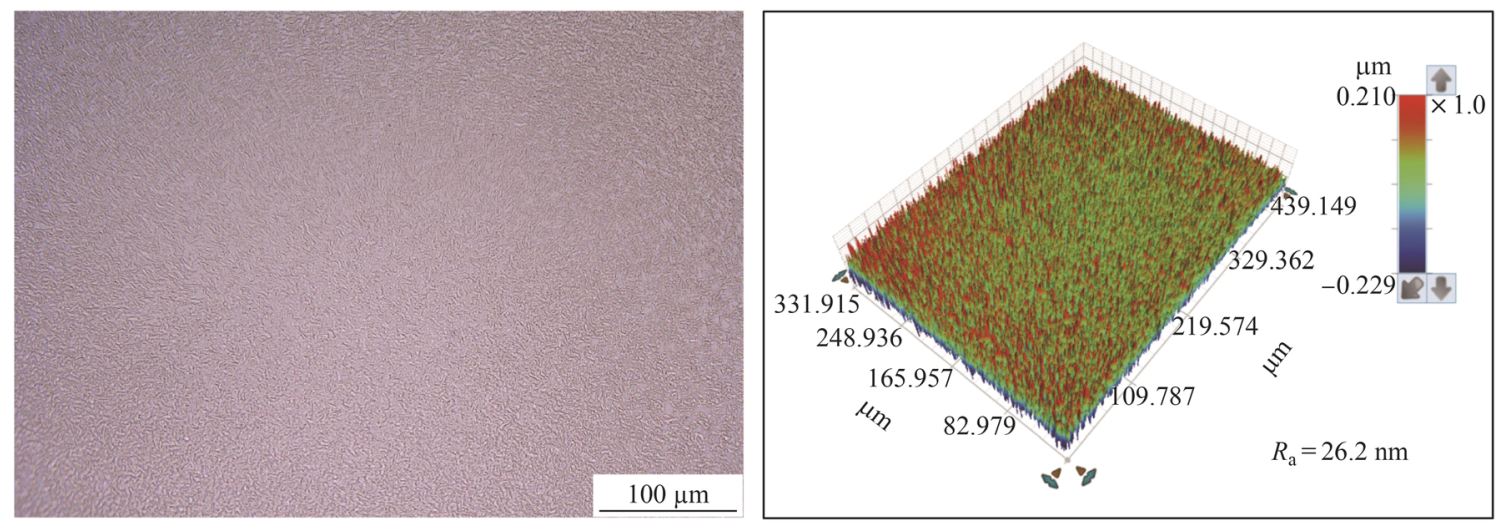

Fig. 11 Electropolished tungsten surface with the $\mathrm{NaOH}$ concentration of $0.27 \mathrm{~mol} / \mathrm{L}$ and duration of $200 \mathrm{~s}$

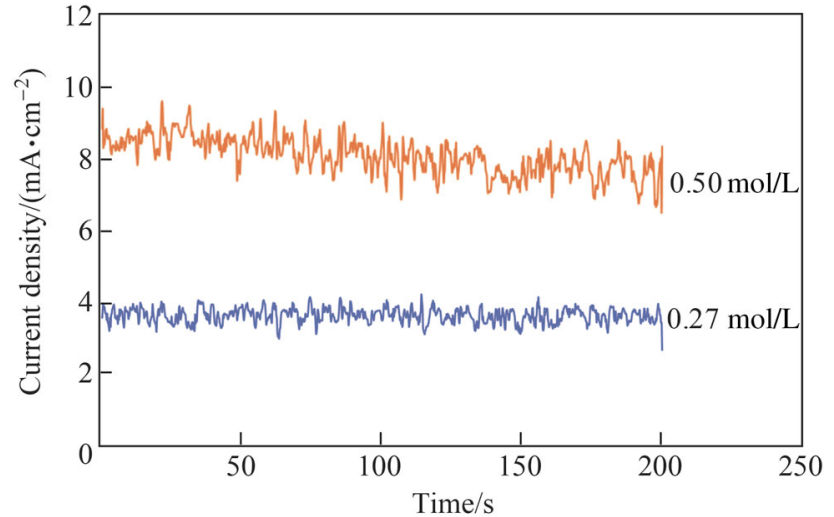

Fig. 12 Current density transitions with the $\mathrm{NaOH}$ concentrations of $0.27 \mathrm{~mol} / \mathrm{L}$ and $0.5 \mathrm{~mol} / \mathrm{L}$

It is assumed that localization effects, which localize the electrochemical dissolution process in a small gap width, are greater when the electrolyte concentration is lower [15], enabling a more prominent electropolishing effect to be realized with a lower $\mathrm{NaOH}$ concentration. The anodic dissolution process favors the nearest position between the anode and cathode electrodes owing to the higher current density, and a lower electrolyte concentration reduces the effective interelectrode gap width for anodic dissolution, resulting in better localization effects and machining accuracy. Furthermore, the lower electrolyte concentration generated comparatively less sludge in the narrow working gap by not only providing lower amounts of precipitates, but also by minimizing the machining allowance. Meanwhile, Krauss et al. [38] investigated the electrochemical behavior of tungsten in electrolytes with different $\mathrm{pH}$ values. It was discovered that a $\mathrm{pH}$ value higher than 12 was not required for the electrochemical dissolution of tungsten, and reactions other than tungsten dissolution did not occur in the high $\mathrm{pH}$ range (approximately 10). In this study, the $\mathrm{pH}$ values of the $\mathrm{NaOH}$ aqueous solution were higher than 13 with the concentrations of $0.25 \mathrm{~mol} / \mathrm{L}$ and $0.5 \mathrm{~mol} / \mathrm{L}$. Therefore, it was assumed that the slight decrease in the minimum $R_{\mathrm{a}}$ with decreasing electrolyte concentration, as shown in Fig. 15, could be limited by the high $\mathrm{pH}$ values of the electrolyte.

In the electropolishing of tungsten with different types of electrolytes, tungsten could not be polished in the concentrated acid electrolyte owing to the oxide film on the surface, and a clear electropolishing effect was obtained in the $\mathrm{NaOH}$ electrolyte. The oxide film on the tungsten surface can be dissolved by reaction (7), resulting in material removal in the $\mathrm{NaOH}$ electrolyte. As for the electropolishing of tungsten in the $\mathrm{NaOH}$ electrolyte, the current density increased with decreasing interelectrode

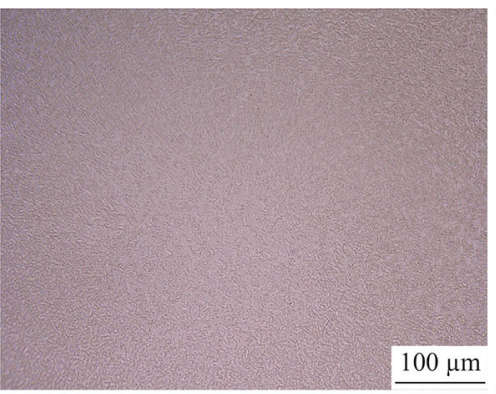

(a) $300 \mathrm{~s}$

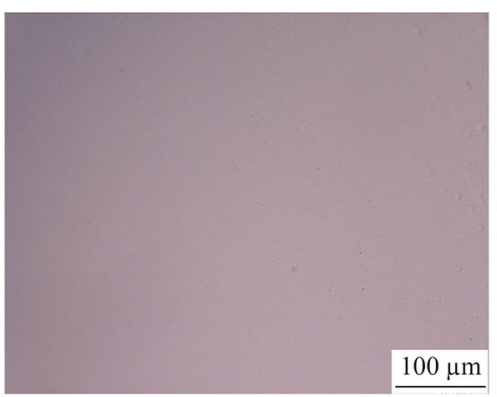

(b) $400 \mathrm{~s}$

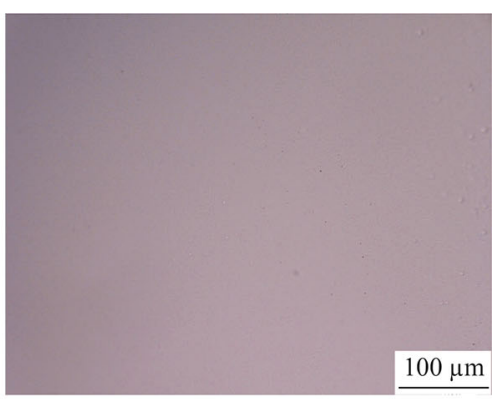

(c) $500 \mathrm{~s}$

Fig. 13 Electropolished tungsten surfaces with different electropolishing durations and the $\mathrm{NaOH}$ electrolyte concentration of $0.27 \mathrm{~mol} / \mathrm{L}$ 


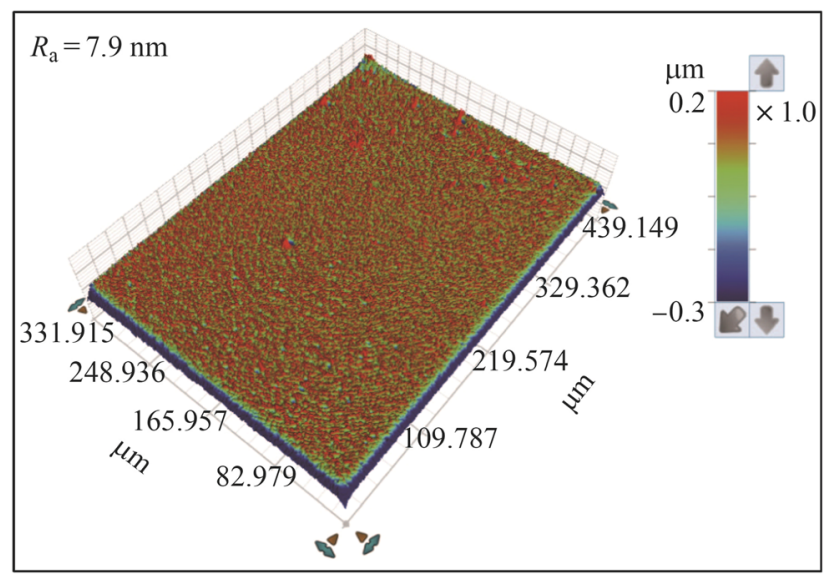

Fig. 14 3D Plot of electropolished tungsten surface with a duration of $400 \mathrm{~s}$ and $\mathrm{NaOH}$ concentration of $0.27 \mathrm{~mol} / \mathrm{L}$

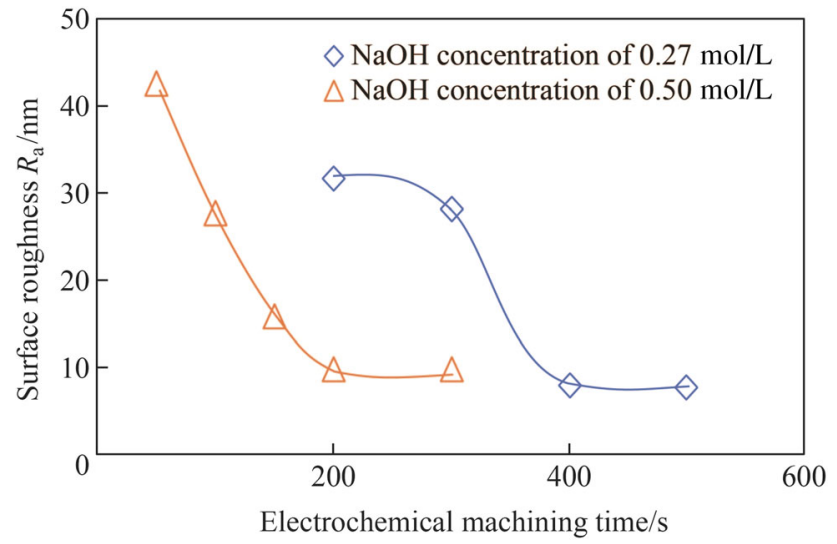

Fig. 15 Surface roughness $R_{\mathrm{a}}$ obtained with different $\mathrm{NaOH}$ concentrations

gap width because of the decreased gap resistance. However, the current density decreased when the interelectrode gap width was extremely narrow because the generated bubbles could not escape from the working gap in time, resulting in increased gap resistance. These electropolishing characterizations exhibit similar features with those obtained from the electropolishing process with the conventional concentrated acid electrolyte. The electropolishing effect was investigated based on different interelectrode gap widths of 3,5 and $7 \mathrm{~mm}$ when electropolishing $316 \mathrm{~L}$ stainless steel with an electrolyte composed of phosphoric acid, sulfuric acid, glycerin, and deionized water [37]. The optimal electrode gap width was $5 \mathrm{~mm}$; however, a smooth surface was achievable with a gap width of $7 \mathrm{~mm}$. The surface roughness was worse when the gap width was $3 \mathrm{~mm}$ because a small gap obstructed the bubbles from escaping from the working gap. However, it was observed that the interelectrode gap width was much larger when the concentrated acid electrolyte rather than the $\mathrm{NaOH}$ electrolyte was used. Because of the high viscosity and a thick viscous film layer formed on the workpiece surface, a larger interelectrode gap width was required for the bubbles to escape from the working gap with the concentrated acid electrolyte.

\subsection{Preparation of copper tool electrode for nanoscale etching}

Figure 16a shows the polarization curve of the copper tool electrode in the $\mathrm{H}_{3} \mathrm{PO}_{4}$ electrolyte. It was obtained by sweeping the applied potential from $2.5 \mathrm{~V}$ to $0 \mathrm{~V}$ (vs Ag/ $\left.\mathrm{AgCl}_{\text {sat }}\right)$ at a scan rate of $-20 \mathrm{mV} / \mathrm{s}$. A limiting current density plateau region is shown clearly in the potential range from $0.35 \mathrm{~V}$ to $1.6 \mathrm{~V}$, and the best electropolishing effect can be obtained in this region [24]. Figure 16b shows the current density transients measured with different applied potentials along the limiting current density plateau region. The current density shows a clear passivation phenomenon at the beginning of the electropolishing, in which the current density decreases quickly with the potential. Subsequently, it shifts to a constant value with

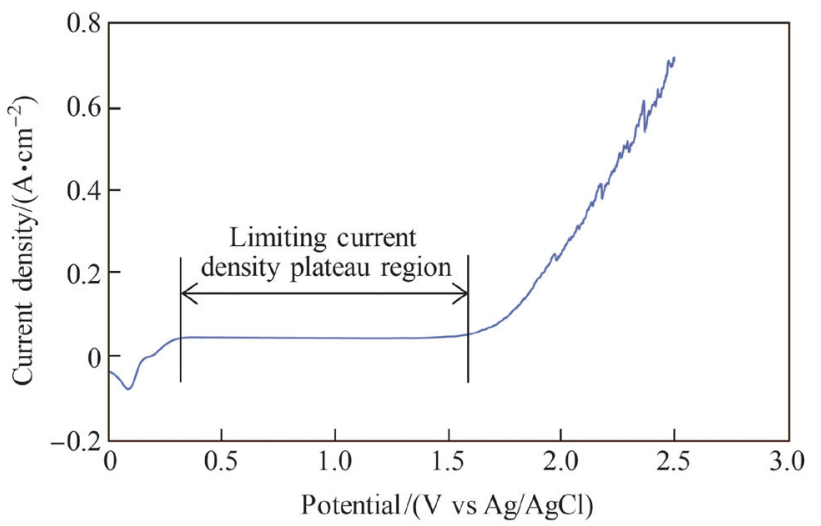

(a)

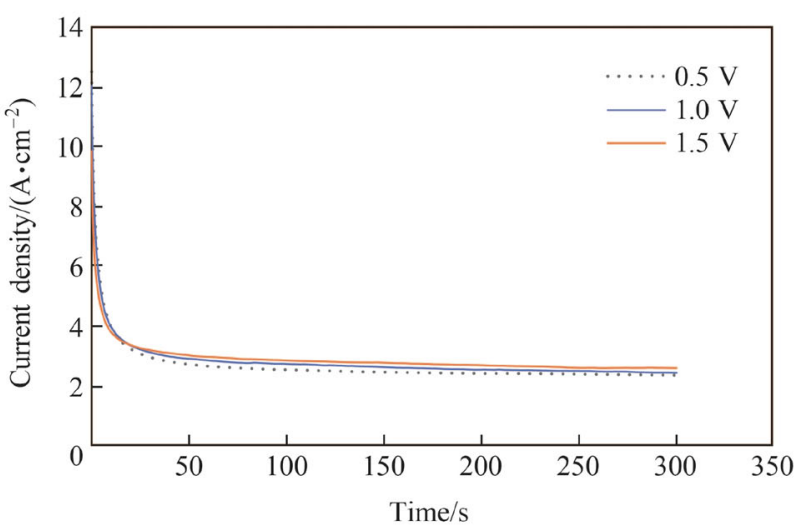

(b)

Fig. 16 a Polarization curve measured with the scan rate of $-20 \mathrm{mV} / \mathrm{s}$ and potential range of $0-2.5 \mathrm{~V}$ and $\mathbf{b}$ current density transient with different applied potentials and electropolishing duration of $300 \mathrm{~s}$ 
increasing electropolishing duration, which is a typical current density transient in the electropolishing process [39]. Because the mass transportation process is limited in the limiting current density plateau region, the current densities are almost the same for the magnitudes of stable current density with different applied potentials. Figure 17 shows the electropolished copper surfaces with different applied potentials corresponding to the current density transients shown in Fig. 16b. The best surface finish was obtained with the high applied potential of $1.5 \mathrm{~V}$, and only a few grain boundaries remained on the electropolished surface. Figure 18 shows the surface counter and 3D plot of the electropolished copper surface with the applied potential of $1.5 \mathrm{~V}$. The $R_{\mathrm{a}}$ was reduced to $18.1 \mathrm{~nm}$ although a few grain boundaries remained. Because the left grain boundaries did not indicate any effect in the subsequent experiments when it was directly used as a tool electrode for nanoscale etching, this electropolished copper tool was used in this study.

\subsection{Nanoscale etching of electropolished tungsten}

Figure 19 shows the current density transients with different etching durations. The current density oscillated significantly because of the effect of gas bubbles generated
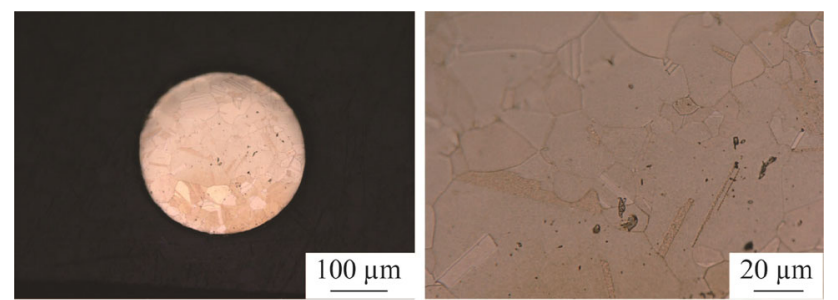

(a) Applied potential of $0.5 \mathrm{~V}$

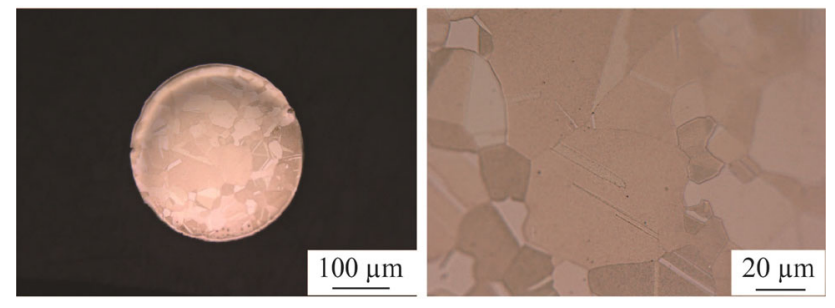

(b) Applied potential of $1.0 \mathrm{~V}$
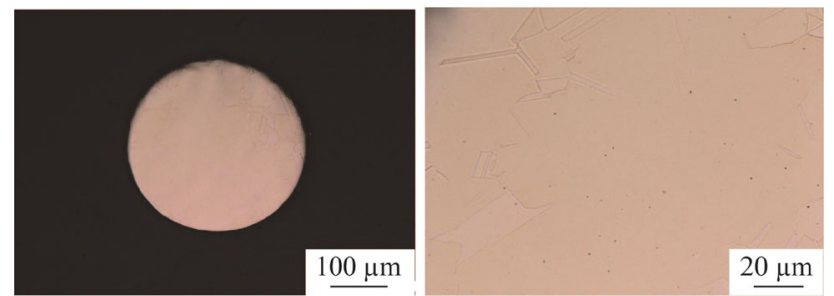

(c) Applied potential of $1.5 \mathrm{~V}$

Fig. 17 Electropolished copper surfaces with different applied potentials

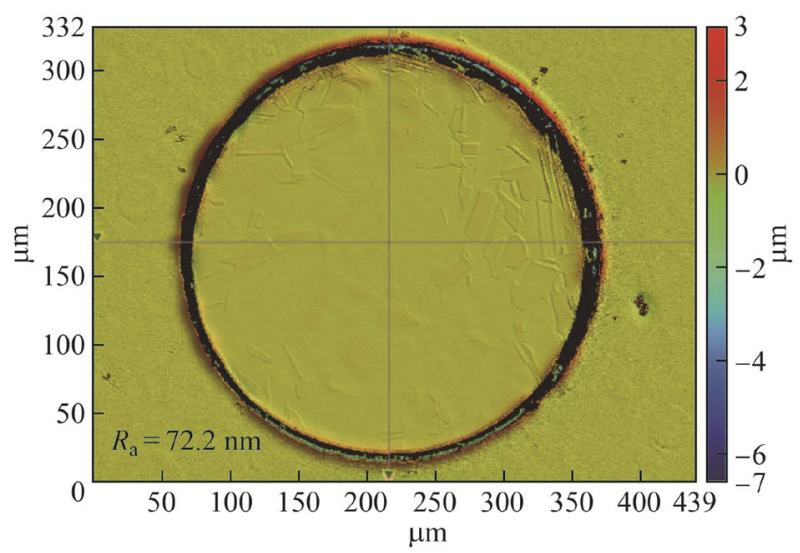

(a) Contour

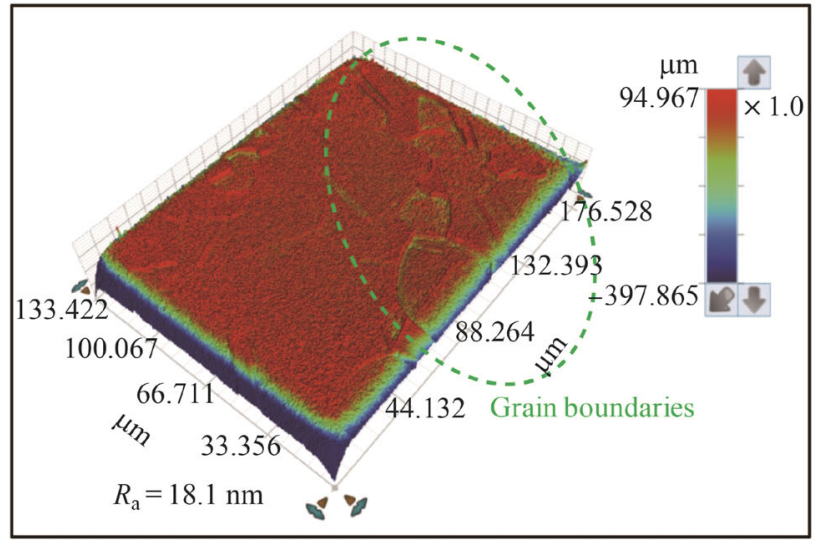

(b) $3 \mathrm{D}$ plot

Fig. 18 Surface counter and 3D plot of the electropolished copper surface with the applied potential of $1.5 \mathrm{~V}$

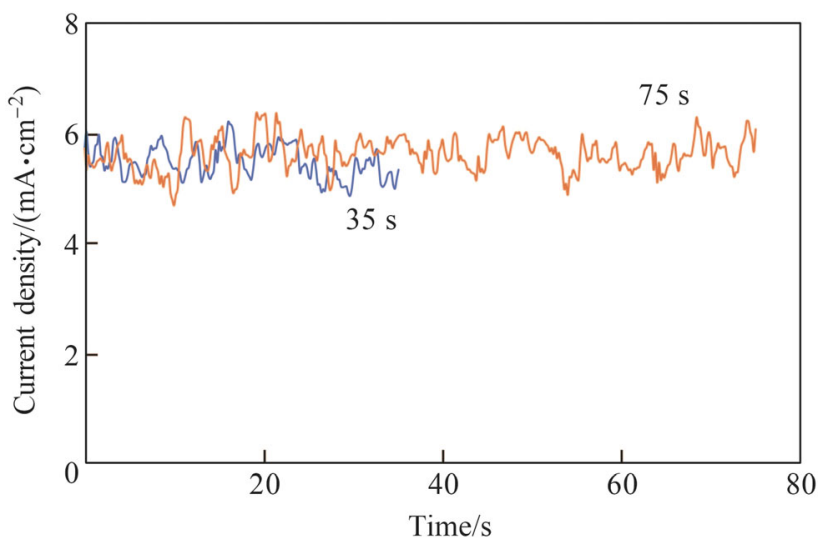

Fig. 19 Current density transients with different etching durations

in the narrow working gap on the gap resistance. Figure 20 shows the results of etching for $75 \mathrm{~s}$. An etched circular area was observed, and the material removal depth was $9.4 \mathrm{~nm}$. Figure 21 shows the results of etching for $35 \mathrm{~s}$. It was difficult to identify the etching area from the contour image; consequently, the material removal depth could not 


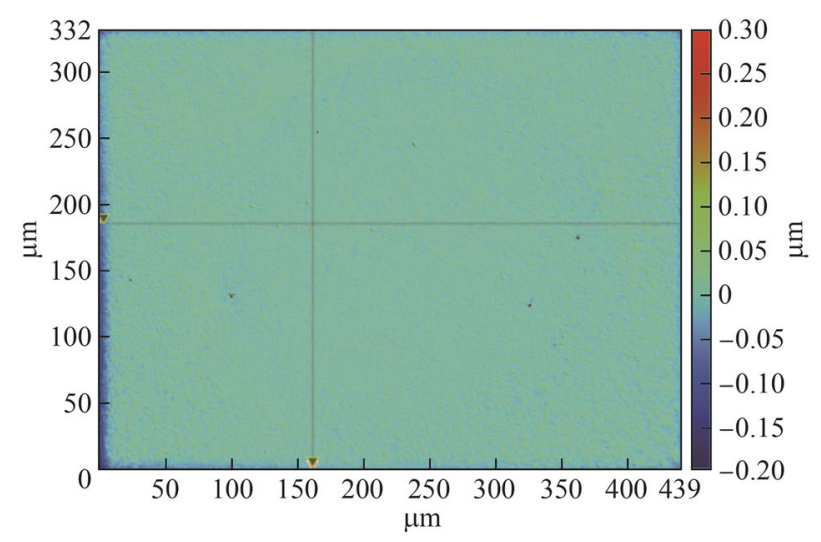

(a) Contour

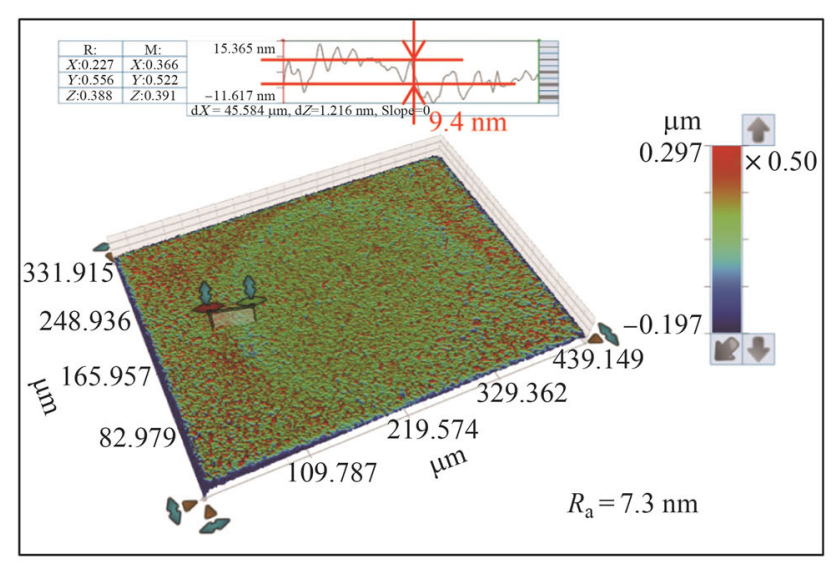

(b) 3D plot

Fig. 20 Etching results with a duration of $75 \mathrm{~s}$

be measured effectively based on the profile, as shown in Fig. $21 b$.

Therefore, the tungsten etched for $35 \mathrm{~s}$ was measured using atomic force microscope (AFM); the results are shown in Fig. 22. Some black lines appeared owing to the effect of noise. The arc " $m n$ " was the etched edge and the lines "AB," "CD," and "EF" crossed the machined edge at different positions. A material removal depth of less than $10 \mathrm{~nm}$ was achieved. Nonetheless, the surface finish of the electropolished tungsten should be further improved in the future because, as shown in Fig. 22, the etched edge was not clear in the three abovementioned lines because of the rough surface. Therefore, the $R_{\mathrm{a}}$ of $7.5 \mathrm{~nm}$ used in this study might have affected the results when the material removal depth was further decreased. Moreover, Fig. 23 shows the amplified image at the machined edge, which shows that the machined edge is not a steep step. This occurred because the etching did not have sufficient localization ability to limit the electrochemical dissolution to a sufficiently small area. It is assumed that a pulse or ultrashort pulse voltage etching can yield a smaller etching removal depth because an electrical double layer on the

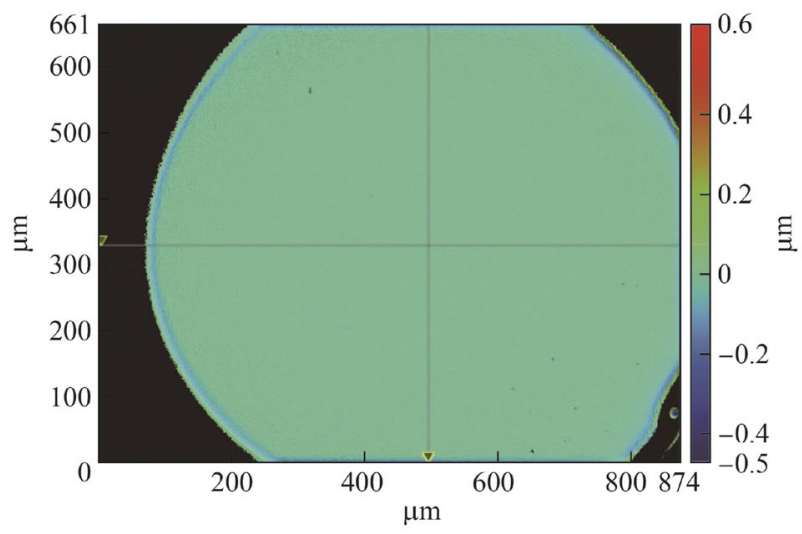

(a) Contour

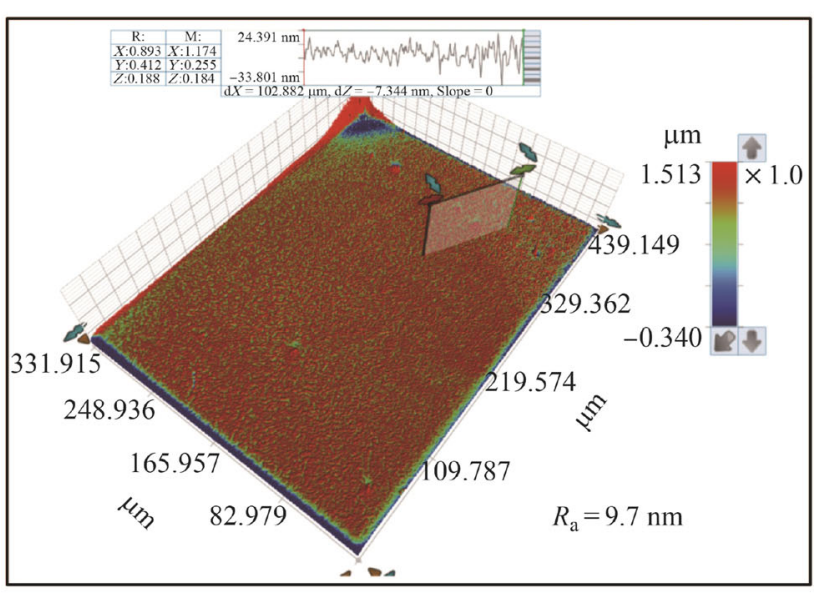

(b) 3D plot

Fig. 21 Etching results with a duration of $35 \mathrm{~s}$

electrode surface can be utilized to localize the electrochemical dissolution in a small working gap [40].

\section{Conclusions}

The electropolishing of tungsten was studied using different types of electrolytes, and the minimum material removal depth on the tungsten surface was investigated using the electrochemical etching method. A smooth surface could not be obtained when the conventional concentrated acid electrolyte was used; on the contrary, a sufficient electropolishing effect was achieved when a $\mathrm{NaOH}$ electrolyte was used. The following conclusions were obtained.

(i) The electropolished tungsten in a concentrated acid electrolyte indicated a slight electropolishing effect owing to the thick oxide film on the tungsten surface. Furthermore, the surface color 

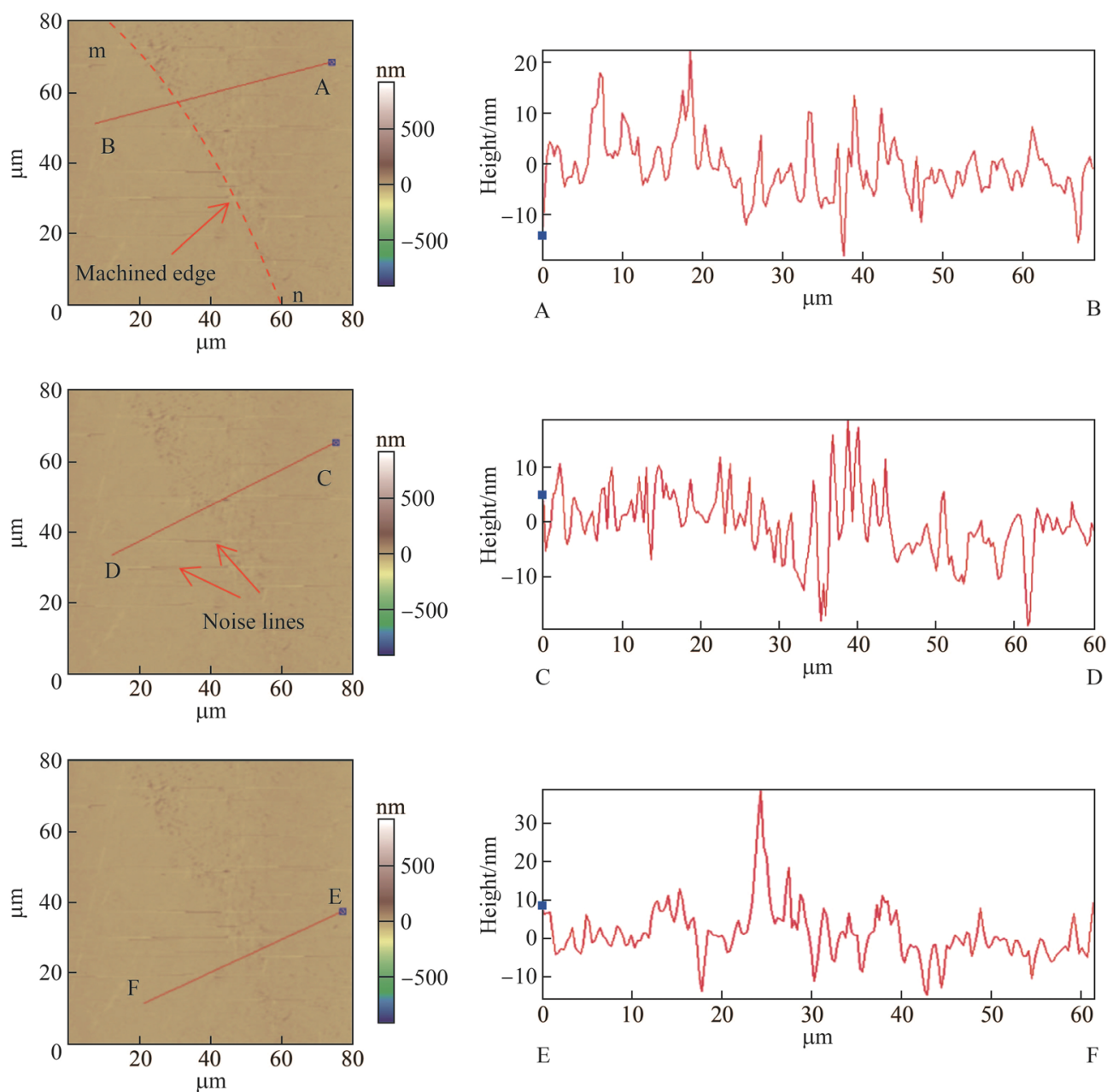

Fig. 22 Etching results with a duration of 35 s measured by AFM ("mn" is the machined edge, "AB," "CD," and "EF" are the three lines crossing the machined edge " $\mathrm{mn}$ " at different positions)
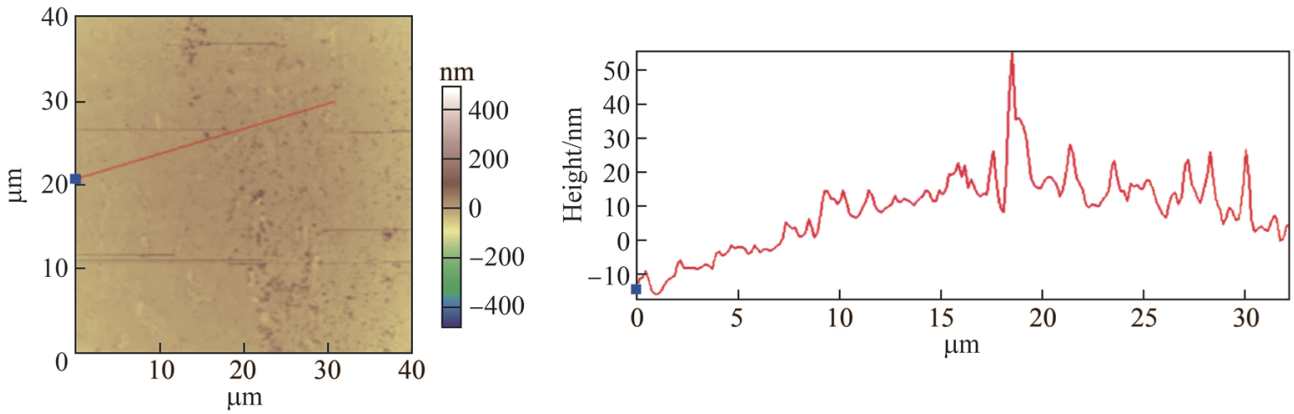

Fig. 23 Amplified image at the etching edge with a duration of $35 \mathrm{~s}$

of tungsten changed after electropolishing because of a change in the oxide film thickness.

(ii) When electropolishing tungsten in a $\mathrm{NaOH}$ aqueous solution, an optimum interelectrode gap width to obtain the best electropolishing effect existed. At an extremely small gap width, the current density decreased because the gas bubbles could not escape from the working gap in time, resulting in a high gap resistance. At a large gap width, the surface finish was deteriorated by the low current density owing to the large gap resistance.

(iii) The $R_{\mathrm{a}}$ decreased from $9.6 \mathrm{~nm}$ to $7.5 \mathrm{~nm}$ when the $\mathrm{NaOH}$ concentration was increased from $0.5 \mathrm{~mol} /$ $\mathrm{L}$ to $0.27 \mathrm{~mol} / \mathrm{L}$. Localization effects were more 
prominent at a lower electrolyte concentration, enabling a more pronounced electropolishing effect to be realized than when a higher electrolyte concentration was used. Furthermore, the lower electrolyte concentrations generated comparatively less sludge in the narrow working gap.

(iv) A material removal depth of less than $10 \mathrm{~nm}$ was achieved when the etching area measured $300 \mu \mathrm{m}$ in diameter on the electropolished tungsten surface. In addition, the machined edge was not a steep step because the ECM did not possess sufficient localization ability to limit the material dissolution process to a sufficiently small area.

Acknowledgements The authors would like to thank the support received from the Science Foundation Ireland (SFI) (Grant No. 15/RP/B3208) and the National Natural Science Foundation of China (NSFC) (Grant No. 61635008). This project has also received funding from the Enterprise Ireland and the European Union's Horizon 2020 Research and Innovation Programme under the Marie SkłodowskaCurie Grant agreement (Grant No 713654).

Open Access This article is licensed under a Creative Commons Attribution 4.0 International License, which permits use, sharing, adaptation, distribution and reproduction in any medium or format, as long as you give appropriate credit to the original author(s) and the source, provide a link to the Creative Commons licence, and indicate if changes were made. The images or other third party material in this article are included in the article's Creative Commons licence, unless indicated otherwise in a credit line to the material. If material is not included in the article's Creative Commons licence and your intended use is not permitted by statutory regulation or exceeds the permitted use, you will need to obtain permission directly from the copyright holder. To view a copy of this licence, visit http://creativecommons. org/licenses/by/4.0/.

\section{References}

1. Fan HG, Tsai HL, Na SJ (2001) Heat transfer and fluid flow in a partially or fully penetrated weld pool in gas tungsten arc welding. Int J Heat Mass Transf 44:417-428

2. Tanaka M, Shimizu T, Terasaki H et al (2000) Effects of activating flux on arc phenomena in gas tungsten arc welding. Sci Technol Weld Join 5:397-402

3. Abyzov AM, Kidalov SV, Shakhov FM (2011) High thermal conductivity composites consisting of diamond filler with tungsten coating and copper (silver) matrix. J Mater Sci 46:1424-1438

4. Ju BF, Chen YL, Fu M et al (2009) Systematic study of electropolishing technique for improving the quality and production reproducibility of tungsten STM probe. Sens Actuators A Phys 155:136-144

5. Kelsey GS (1977) The anodic oxidation of tungsten in aqueous base. J Electrochem Soc 124:814-819

6. Han W, Kunieda M (2019) A novel method to switch machining mode between micro-ECM and micro-EDM using oxide film on surface of tungsten electrode. Precis Eng 56:455-465

7. Wang J, Fang FZ, Yan G et al (2019) Study on diamond cutting of ion implanted tungsten carbide with and without ultrasonic vibration. Nanomanuf Metrol 2:177-185
8. Wang XL, Han LH, Geng YQ et al (2019) The simulation and research of etching function based on scanning electrochemical microscopy. Nanomanuf Metrol 2:160-167

9. Fang FZ, Zhang N, Guo D et al (2019) Towards atomic and close-to-atomic scale manufacturing. Int J Extrem Manuf 1:1-33

10. Fang FZ, Xu F (2018) Recent advances in micro/nano-cutting: effect of tool edge and material properties. Nanomanuf Metrol $1: 4-31$

11. Suzuki N, Haritani M, Yang J et al (2007) Elliptical vibration cutting of tungsten alloy molds for optical glass parts. CIRP Ann Manuf Technol 56:127-130

12. Sarkar S, Sekh M, Mitra S et al (2008) Modeling and optimization of wire electrical discharge machining of $\gamma$-TiAl in trim cutting operation. J Mater Process Technol 17:525-536

13. Chen HC, Lin JC, Yang YK et al (2010) Optimization of wire electrical discharge machining for pure tungsten using a neural network integrated simulated annealing approach. Expert Syst Appl 37:7147-7153

14. Yang RT, Tzeng CJ, Yang YK et al (2012) Optimization of wire electrical discharge machining process parameters for cutting tungsten. Int J Adv Manuf Technol 60:135-147

15. Masuzawa $T$ (2000) State of the art of micromachining. CIRP Ann Manuf Technol 49:473-488

16. Reinhardt KA, Kern W (2018) Handbook of silicon wafer cleaning technology, 3rd edn. William Andrew, Park Ridge

17. Fang FZ, Zhang XD, Gao W et al (2017) Nanomanufacturingperspective and applications. CIRP Ann Manuf Technol 66:683-705

18. Bielmann M, Mahajan U, Singh RK (1999) Effect of particle size during tungsten chemical mechanical polishing. Mater Res Soc Symp Proc 2:401-403

19. Larsen-Basse J, Liang H (1999) Probable role of abrasion in chemo-mechanical polishing of tungsten. Wear 233(235):647-654

20. Nanz G, Camilletti LE (1995) Modeling of chemical-mechanical polishing: a review. IEEE Trans Semicond Manuf 8(4):382-389

21. Wang F, Zhang X, Deng H (2019) A comprehensive study on electrochemical polishing of tungsten. Appl Surf Sci 475:587-597

22. Han W, Fang FZ (2020) Investigation of electrochemical properties of electropolishing Co-Cr dental alloy. J Appl Electrochem 50:367-381

23. Han W, Fang FZ (2020) Two-step electropolishing of $316 \mathrm{~L}$ stainless steel in a sulfuric acid-free electrolyte. J Mater Process Technol 279:116558

24. Han W, Fang FZ (2019) Fundamental aspects and recent developments in electropolishing. Int J Mach Tools Manuf 139:1-23

25. Schubert N, Schneider M, Michaelis A et al (2018) Electrochemical machining of tungsten carbide. J Solid State Electrochem 22:859-868

26. Han W, Fang FZ (2019) Electropolishing of 316L stainless steel using sulfuric acid-free electrolyte. J Manuf Sci Eng 141:101015

27. Hu YN, Zhou H, Liao LP et al (2003) Surface quality analysis of the electropolishing of cemented carbide. J Mater Process Technol 139:253-256

28. Holstein N, Krauss W, Konys J et al (2016) Advanced electrochemical machining (ECM) for tungsten surface micro-structuring in blanket applications. Fusion Eng Des 109:956-960

29. Lee ES, Shin TH (2011) An evaluation of the machinability of nitinol shape memory alloy by electrochemical polishing. J Mech Sci Technol 25:963-969

30. Rajurkar KP, Zhu D, McGeough JA et al (1999) New developments in electro-chemical machining. CIRP Ann Manuf Technol 48:567-579 
31. Piotrowski O, Madore C, Landoly D (1998) The mechanism of electropolishing of titanium in methanol-sulfuric acid electrolytes. J Electrochem Soc 145:2362-2369

32. Anik M (2006) Effect of concentration gradient on the anodic behavior of tungsten. Corros Sci 48:4158-4173

33. Anik M, Osseo-Asare K (2002) Effect of $\mathrm{pH}$ on the anodic behavior of tungsten. J Electrochem Soc 149:B224-B233

34. Di PA, Di QF, Sunseri C (1980) Anodic oxide films on tungstenI. The influence of anodizing parameters on charging curves and film composition. Corros Sci 20:1067-1078

35. Evans TE, Hart AC, Skedgell AN (1973) The nature of the film on coloured stainless steel. Trans IMF 51:108-112

36. Shimasaki T, Kunieda M (2016) Study on influences of bubbles on ECM gap phenomena using transparent electrode. CIRP Ann Manuf Technol 65:225-228

37. Zhang R, Ivey DG (1996) Preparation of sharp polycrystalline tungsten tips for scanning tunneling microscopy imaging. J Vac Sci Technol B Microelectron Nanom Struct 14:1-10

38. Krauss W, Holstein N, Konys J (2007) Strategies in electrochemical machining of tungsten for divertor application. Fusion Eng Des 82:1799-1805

39. Park JJ, Il PS, Lee SB (2004) Growth kinetics of passivating oxide film of Inconel alloy 600 in $0.1 \mathrm{M} \mathrm{Na}_{2} \mathrm{SO}_{4}$ solution at 25-300 ${ }^{\circ} \mathrm{C}$ using the abrading electrode technique and ac impedance spectroscopy. Electrochim Acta 49:281-292

40. Schuster R, Kirchner V, Allongue P et al (2000) Electrochemical micromachining. Science 289:98-111

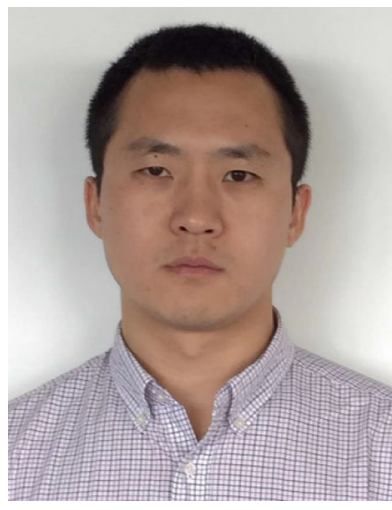

ultra-short pulse current.
Wei Han is a Marie Sklodowska-Curie Career-FIT Research Fellow at the Centre of Micro/ Nano Manufacturing Technology (MNMT-Dublin) at University College Dublin. He received his Ph.D. from The University of Tokyo, Japan in 2016. His research interests focus on the development of eco-friendly electrolyte for the electropolishing of biomedical devices and the micro-electrochemical machining of easily passivated materials using an

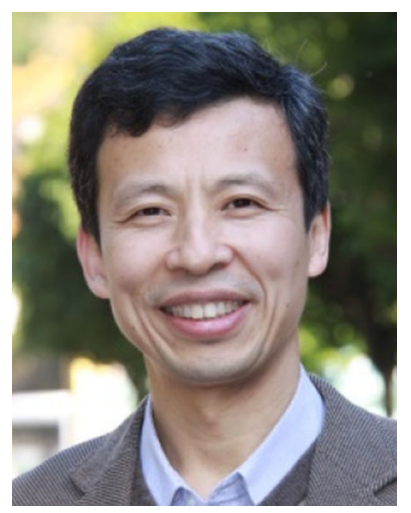

Feng-Zhou Fang is a joint Professor and the director of Centre of Micro/Nano Manufacturing Technology (MNMT) at Tianjin University and University College Dublin. He has been doing both fundamental studies and application development in the areas of optical freeform design and manufacturing, bio-medical manufacturing, ACSM, ultraprecision machining and measurement benefiting a variety of industries in medical devices, bio-implants, optics and mold sectors. 